\title{
Genetics and flower formation of annual Lunaria ${ }^{1}$
}

\author{
S. J. Wellensiek \\ Department of Horticulture, Agricultural University, Wageningen, the Netherlands
}

Received: 30 March 1973

\section{Summary}

The genetical and environmental requirements for flower bud formation of Pierik's annual Lunaria mutant were studied in comparison with its biennial parent.

The biennial parent can only be induced to flower formation by plant vernalization and hence is absolutely cold requiring. Long day (LD) has no inducing action.

The annual mutant can be induced to flower formation by vernalization, but also by $\mathbf{L D}$. Preliminary evidence shows that LD favours stem elongation.

Biennial flowering is dominant over annual flowering and the difference is monogenic. The dominant gene prevents LD induction. Through the mutation LD induction has become possible.

\section{Introduction}

After studying progenies from 48 different locations in 17 countries Pierik (1967) concluded that annual flowering in Lunaria annua L. did not occur. Wellensiek (1958) had found that flower formation only takes place when plants of a certain age are exposed to a vernalizing cold period. Therefore, the ordinary Lunaria or 'honesty' is a typical biennial plant, which is reflected in the name Lunaria biennis Moensch. Unfortunately, this name is taxonomically illegitimate and $L$. annua $\mathrm{L}$. is the misleading legitimate name.

Pierik (1967) applied a mutagenic seed treatment of biennial Lunaria with ethyl methane sulphonate and was fortunate enough to find one fertile annual plant among some 10000 viable plants in $\mathbf{M}_{2}$. This mutant was constant in $\mathbf{M}_{3}$ and was the startingmaterial for the present study, which involves the genetics of the mutant, its conditions for flower bud formation, and leads to a specification of the nature of the mutation.

\section{Genetics}

In the following, 'biennial' is used to indicate the absolute cold requirement, as is found in the common biennial Lunaria. 'Annual' means flowering without a cold treatment, as in Pierik's annual mutant. The crosses biennial $\times$ annual and reciprocally yielded biennial $F_{1}$ plants, which segregated in $F_{2}$ into 599 biennial: 137 annual. The expectation according to $3: 1$ is $552: 184$, with actual deviation divided by standard

1 Publication 388, Laboratorium voor Tuinbouwplantenteelt, Landbouwhogeschool, Wageningen, the Netherlands. 
deviation of 4.0 , so that a monogenic segregation is far from evident. However, Pierik's observation that seeds of the annual mutant germinate relatively poorly was confirmed. In strictly comparable material annual seeds germinated for $59 \%$, and biennial seeds for $99 \%$. If a correction is applied to the number of annual $\mathrm{F}_{2}$ 's, supposing that only $59 \%$ of them has germinated, the $\mathrm{F}_{2}$ would have been composed of 599 biennials : 192 annuals and this fits the expection of $593: 198$ quite well.

Since this way of calculation, how attractive it may be, leaves some doubt, an $F_{3}$ was grown of 48 biennial $F_{2}$ plants, which flowered in a greenhouse after natural vernalization in the field. In case of monogenic segregation the expectation is that 1 out of $3 F_{2}$ plants is homozygous, while 2 are heterozygous. The former throw a constant progeny, while the latter segregate. In case of self-fertilization the heterozygous $F_{2}$ 's segregate into 3 biennial : 1 annual. In case of complete cross-fertilization this segregation becomes $5: 1$. The actual segregation will be somewhere in between those ratios, if not a poor germination of the annuals induces a deficiency of recessives. Especially on account of the last consideration, the segregations within each line were not determined, but only the segregation as such. In order to obtain reliable results, the original numbers of plants per $F_{3}$ line were rather large, namely 100 .

Of the $48 \mathrm{~F}_{3}$ lines, 15 turned out to be constant biennial and 33 segregated in biennial and annual. This fits the expectation of $16: 32$ so well that biennial and annual can be considered as monogenically different with biennial as dominant.

\section{Flower-inducing factors}

During the genetical investigations, which also involved the growing of parental annuals in different seasons, a great variation in the time from sowing to flowering in these annuals was observed. Pierik observed the first flower 8 weeks after sowing. In my material the shortest time was 33 days, in full summer, but the longest period approached 6 months, in winter and spring. The variation in number of days from sowing to first visible flower-bud was always rather great, even within one sowing. Coefficients of variability from 20 to $25 \%$ illustrate this.

Light intensity was assumed to be a determining factor, but as far as the experience went it is not specific and influences flower bud formation only indirectly by influencing the growth rate, which is in harmony with Higazy (1962). This was different regarding daylength. A preliminary experiment on the influence of photoperiod yielded:

8 hours, 0 out of 20 plants flowering

12 hours, 1 out of 18 plants flowering exceedingly late

16 hours, 17 out of 18 plants flowering relatively early.

This suggested that annual Lunaria is a long-day plant.

In a more detailed experiment not only daylength, but also vernalization was involved. Ten-week-old plants were vernalized during 10 weeks at $5^{\circ} \mathrm{C}$ under 8 hours light per day. The controls were of the same age, but unvernalized and grown in short days of 8 hours at greenhouse temperatures. After the completion of the vernalization the vernalized plants $(+\mathrm{V})$ and the unvernalized ones $(-\mathrm{V})$ were exposed to short days of 8 hours (SD) or to long days of 16 hours (LD), both in an ordinary greenhouse. This made 4 treatments in all, each with originally 35 plants. The numbers of flowering plants per treatment and the number of days from the beginning of the aftertreatment until the appearance of the first flower bud per plant were determined. The results are: 


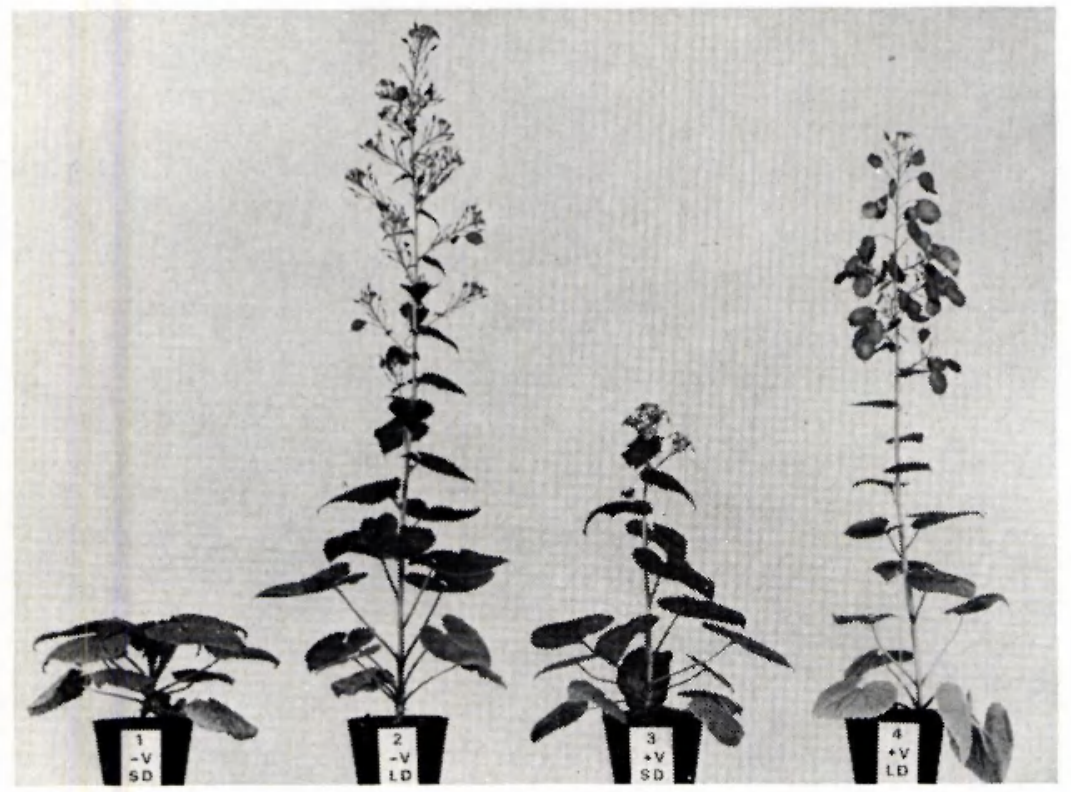

Fig. 1. Representative plants of annual Lunaria: 1. unvernalized, followed by short day; 2 . unvernalized, followed by long day; 3 . vernalized, followed by short day; 4 . vernalized, followed by long day. Photograph was taken 53 days after the completion of the vernalization.

\begin{tabular}{|c|c|c|c|}
\hline & & number & days \\
\hline 1. $-\mathrm{V}$ & SD & {$[3 / 35$} & $98.3]$ \\
\hline 2. $-V$ & LD & $33 / 33$ & $26.9 \pm 0.78$ \\
\hline 3. $+\mathrm{V}$ & SD & $34 / 34$ & $29.3 \pm 0.89$ \\
\hline 4. $+\mathrm{V}$ & LD & $33 / 33$ & $13.8 \pm 0.50$ \\
\hline
\end{tabular}

It is clear that the effect of the 1st treatment can be neglected. Treatments 2 and 3 gave a difference of $2.4 \pm 1.18$ days, which has hardly any significance. Treatments 2 and 3 against Treatment 4 differed very significantly.

The conclusion is that annual Lunaria is induced to flower formation by long day and by vernalization, while their combination accelerates the appearance of flower buds.

Fig. 1 illustrates the results. It is noticeable that the stem lengths are very different. This was confirmed by measurements of stems of 10 representative plants, yielding for Treatments 2,3 and 4 averages of $51.6 \pm 2.72,26.7 \pm 1.38$ and $43.7 \pm 1.66 \mathrm{~cm}$, respectively. Hence Treatments 2 and 4 resulted in decidedly longer stems than Treatment 3 , indicating that LD has a strong stem-elongating effect. However, no definite conclusion can be drawn from the figures, since they were determined long after the onset of flower bud formation. To study the effects of the treatments on stem elongation, periodical measurements should have taken place. We conclude to a preliminary indication that LD influences stem elongation favourably.

\section{Discussion}

The dominance of biennial Lunaria over its annual mutant is just opposite to a comparable case, viz Brussels sprouts, where annual is dominant (Wellensiek, 1960). 
However, both cases correspond in the deficiency of annuals in crosses. In Brussels sprouts this could be explained by hidden variability of the rate of flower formation in the biennial parent, inducing some late, even not at all flowering annuals. In Lunaria a more acceptable explanation is the poor germination of annuals.

A comparison of the floral induction of biennials and annuals leads to an unexpected conclusion. In the following two schemes the same symbols are used as before. Furthermore: $-=$ no effect, $+=$ effect, $++=$ strong effect.

biennial

\begin{tabular}{|c|c|c|c|c|c|}
\hline & SD & LD & & SD & LD \\
\hline$-\mathrm{V}$ & - & - & $-V$ & - & + \\
\hline$+\mathrm{V}$ & + & ++ & $+V$ & + & $+t$ \\
\hline
\end{tabular}

The strong effect in biennial of $+\mathrm{V}$ followed by $\mathrm{LD}$ must be ascribed to the rate of realization after induction by vernalization, since $L D$ in itself is ineffective. It is plausible that the same effect of LD after vernalization occurs in annual. The essential difference between biennial and annual turns out to be not the reaction to vernalization, but to LD. Biennial does not react, but annual does.

This has definite consequences for the action of the dominant gene in biennial. Evidently this gene prevents the possibility of reaction to $\mathrm{LD}$ as inducing factor. The mutation into its recessive allelomorph opens up this possibility in annual. Hence LD reaction - or its prevention - is gene determined. Whether vernalizability is also gene determined cannot be judged from the present material, because all plants reacted to vernalization. If a gene for vernalizability would occur, it must be different from the LD gene.

The annual Lunaria mutant offers an interesting case, because floral induction is possible by vernalization, but also by $L D$. A similar case is Silene armeria $L$. (see Wellensiek, 1969). The latter species can also be induced to flower formation by very high temperature, and in certain genotypes by $\mathrm{GA}_{3}$. The effect of very high temperature on biennial Lunaria is completely negative (unpublished), while $\mathrm{GA}_{3}$ has no complete floral inducing effect (Wellensiek, 1960, p. 160). It would be worth-while to study the effects of high temperature and of $\mathrm{GA}_{3}$ on annual Lunaria.

\section{References}

Higazy, M. K. M. T., 1962. Shortening the juvenile phase for flowering. Meded. LandbHogesch. Wageningen 62 (8): 1-53.

Pierik, R. L. M., 1967. Regeneration, vernalization and flowering in Lunaria annua L. in vivo and in vitro. Meded. LandbHogesch. Wageningen 67 (6): 1-71.

Wellensiek, S. J., 1958. Vernalization and age in Lunaria biennis. Proc. Kon. Ned. Akad. Wet. C61: 561-571.

Wellensiek, S. J., 1960. Annual Brussels sprouts. Euphytica 9: 10-12.

Wellensiek, S. J., 1960. Stem elongation and flower initiation. Proc. Kon. Ned. Akad. Wet. C63: 159-166.

Wellensiek, S. J., 1969. Silene armeria L. In: Evans, L.T. (Ed.), The induction of flowering, p. 350-363, MacMillan of Australia. 